\title{
Cambios en Washington Notas para un nuevo debate
}

\author{
Xabier Gorostiaga, S.J.
}

No acaba de perfilarse con claridad la dialéctica de cambios que se están produciendo en Washington y que afectan a Nicaragua y Centroamérica.' EI tema del impacto de la administración Clinton en la región centroamericana reaparece una y otra vez entre nosotros, sin que salgamos de dudas y perplejidades y encontremos claridad suticiente para tomar posiciones.

Las recientes declaraciones del Subsecretario de Estado, Alexander Watson, y del nuevo Embajador norteamericano en Managua, John Maisto, han creado expectativas positivas. Se aprecia claramente un nuevo estilo, un cambio de tono, de énfasis y de forma. También un cambio de fondo. La política de la confrontación y contención ("containment") parece superada. La nueva política se define en torno a la promoción y defensa de la democracia de mercado. Se define la democracia como el "proceso para satisfacer mejor las necesidades compartidas ante deseos competitivos", y el mercado como "el proceso para satisfacer mejor las necesidades privadas y expandir las oportunidades".

1. En diversos debates en el Diálogo Interamericano, en el Wilson Center, (Mayo 1993) en el Camegie Endowment (octubre 1993), en el propio Congreso Norteamericano (octubre 93).

2. Anthony Lake, Asistente del Presidente de Asuntos de Seguridad Nacional "From Containment to Enlargement" (21, septiembre 1993, Johns Hopkins University, Washington, D.C.) Pág. 3) 
Es evidente que hay un cambio de una diplomacia de procónsules en la época de Reagan-Bush a una diplomacia de búsqueda del consenso, del diálogo y de la estabilidad. Algunos le llaman a esta diplomacia de "tutelaje matizado", promotora de la autonomia y el respeto. Otros consideran que no hay en ella un trasfondo de nuevas relaciones que permita una asociación autónoma y equitativa.

La frase más socorrida en Washington para referirse a Nicaragua y a Centroamérica es la de "benign neglect" (olvido benigno). En un trabajo presentado ante la Comisión Sanford Arturo Cruz junior calificaba esla marginación regional como una situación en la que estamos "huérfanos de imperio"3 Por su parte, Oscar Arias la calilicaba como "la frontera del olvido después del fin de la guerra en Centroamérica. La nueva situación crea una conlradicción paradójica: molestos cuando intervienen, frustrados cuando nos abandonan.

Sin embargo, no existe en Estados Unidos una politica homogénea para Centroamérica. En El Salvador el Senador Mockley jugó un papel definitivamente constructivo, pacificador y democrático. Nicaragua no tuvo esa suerte con el Senador Helms, que reprodujo las peores políticas de la guerra fria. Elliot Abrams justificaba esa diferencia con esle argumento: "En El Salvador hemos ganado la guerra. En la victoria podemos ser generosos. Pero aqul no hemos ganado, más o menos ha ganado el sandinismo. Es como en Vietnam... Es una parte de la vieja guerra fría y de la vieja guerra con Nicaragua". 4

Frente a esta actitud dura, las declaraciones de Alexander Watson y del Embajador Maisto revelan un nuevo estilo y prometen un nuevo contenido. Podría decirse que pretenden cerrar decorosamente la crisis WashingtonManagua sin victoria, aunque exigiendo el desmontaje del EPS de manera similar a como se negoció el desmontaje del FMLN. El control civil sobre los militares - de indudable importancia y necesidad para consolidar la democracia en todos los pueblos- no se puede aplicar en Nicaragua con las mismas exigencias que en Guatemala, El Salvador y Honduras o que en Chile o Perú. La situación de Haitl abre nuevos integrantes sobre la política de Estados Unidos hacia los militares y trae recuerdos del viejo estilo del doble estandard.

3. Arturo J. Cruz, Jr.: "La Nueva Politica Exterior de Estados Unidos" más allá de un cambio de administración. (Nicaragua, Marzo, 1993).

4. Xabier Gorostiaga: "La Paz Imposible?" Entrevisla con Elliott Abrams, "El Semanario" (26 de sepliembre de 1993) y Wilson Center "Noticias", the Latin American Program. Septiembre 93. 
La posición, reafirmada insistentemenle, de apoyar las instituciones democráticas, no aparece con igual transparencia cuando se trata de personalidades tan diferentes como el Presidente Arístides, el Presidente Cristiani o la Presidenta Barrios de Chamorro. Lo que demuestra que las personalidades y su capacidad de negociación definen también los márgenes del apoyo institucional.

La conocida frase "el problema lo resuelven los nicaragüenses" o los salvadoreños o los haitianos, no tiene el mismo significado en cada uno de estos palses. ¿Se debe esto a una doble politica y a un maquiavelismo imperialista? ¿O la situación es más compleja y tiene otras coordenadas de interpretación? Llenarse la boca con viejos epítetos y esquemas no sirve hoy, oculta la incapacidad para analizar las situaciones actuales, más complejas que las del pasado.

\section{Algunos factores determinantes}

Hoy, Centroamérica es considerada una región irrelevante. Estamos marginados de la agenda norteamericana y de la agenda internacional. Incluso en discursos y pronunciamientos que prelenden enfatizar el interés de Estados Unidos por el "enlargement" - por el compromiso y el involucramiento en los temas internacionales--. Centroamérica no es mencionada ni una sola vez, mucho menos Nicaragua.

Lo sorprendente es que tampoco América Latina es mencionada, exceptuando el tema de la defensa de la democracia en Guatemala y Haitl. Ni México ni Brasil ni Chile ni Argentina ni los otros grandes palses de América Latina son mencionados una sola vez. La palabra América Latina no aparece, a no ser que se identifique con la palabra NAFTA, el Tratado de Libre Comercio. La Comunidad Económica Europea, Japón, los paises del Paclfico, Rusia, los paises de Centro y Europa Oriental, Sudalrica y Nigeria en el continente africano, junto con China y el mundo islámico, aparecen como las áreas más importantes del mundo. No sólo es irrelevante Centroamérica sino que América Latina es asumida como una realidad de las "emerging Western Hemisferic Community of Democracies", (emergentes comunidades democráticas del hemisferio Occidental). Como dijo un agudo analista norteamericano recientemente, "América Latina is take for granted" (América Latina está garantizada, se da por descontada).

La crisis del NAFTA - sobre todo, después de la derrota de los conservadores en Canadá y ante las próximas elecciones en Méxicopudiera convertirse en una Caja de Pandora que obligue a Estados Unidos a buscar una relación con América Latina más precisa y con más 
contenido que el mero anuncio de promover "market democracies". En muchos paises las democracias están muy tiemas para poder ser llamadas democracias y el mercado debe ser construido, estabilizado, ampliado y sobre todo, democratizado para que funcione en una forma eficiente, estable y con capacidad de resolver el creciente aumento de la pobreza, el desempleo y el desastre ecológico. En Nicaragua, la democracia y el mercado están en construcción y crisis. En los tres últimos años las contradicciones de esta democracia de mercado se han hecho cada vez más patentes, al no existir todavia ni las instituciones maduras de la democracia (Asamblea, Corte Suprema Estado de Derecho) ni los mecanismos e instituciones sociales de un auténtico mercado nacional.

¿Quiere decir esto que los cambios en Washington son meramente cosméticos? ¿Que estas nuevas oportunidades son puros espejismos? ¿Que estos nuevos retazos de política no acaban de definir una Ilnea coherente hacia América Latina? ¿Que el "beningn neglect" es una politica suliciente para estos tiempos diffiles?

En términos nicas, algunos irónicos podrlan decir que la politica de la administración Clinton para Nicaragua es un "nacatamal pindongo", sin carne ni contenido.

\section{Un intento de aproximación al teme}

Estados Unidos está sufriendo una profunda transición. La guerra fría le permitió definir claramente politica de contención (containment). Incluso en los períodos en que Reagan llegó a calificar a Centroamérica $-\mathrm{y}$ a Nicaragua en ella - como la región más estratégica del mundo, no tenla una politica espec/fica para Nicaragua y Centroamérica, sino que aplicaba a la región su política de contención global del comunismo.

Estados Unidos está hoy buscando una nueva politica exterior, pero la administración Clinton no acaba de encontrar la fórmula para definirla. ¿Son fuerzas fuera de la administración las que la definen? ¿Son algunos sectores del Departamento de Estado, el Tesoro y Defensa los que lo hacen? ¿Es el National Security Council? Pareciera que un conjunto de 'lobbies' difundidos en las estructuras del poder politico y económico, en los medios de comunicación social, en la industria militar, la banca y las empresas transnacionales y en los grupos de poder federal de los diferentes Estados, los que juegan este papel, que es hoy más fragmentado y variado que en los tiempos del desaparecido "imperio del maln cuya amenaza los aglutinaba. A pesar de lo fragmentado de este poder de decisión, lograron alcanzar consensos suficientes en el perlodo de la guerra fria, porque eran tiempos de expansión del poder económico, 
mililar y político norteamericano. Pero hoy estos núcleos de poder no acaban de encontrar suficiente consenso. La debilidad de la administración Clinton -al no formar un nuevo equipo de gobiemo y seguir integrada en gran parte por funcionarios de otra débil administración democrática, la de Carter unida a la debilidad del lobby latinoamericano en Washington, no consiguen sistematizar el consenso suliciente para delinir la politica exterior de Estados Unidos. Mucho menos, para América Latina.

Los últimos discursos del Presidente Clinton, del Secretario de Estado Warren Chistopher y del Asesor presidencial Anthony Lake son lo suficientemente generales y ambiguos como para dar la sensación de que hay una politica sin tenerla. Esta ambigūedad repercute en forma negativa en América Latina, pero especialmente en Centroamérica y sobre todo en Nicaragua, donde la crisis sigue inconclusa sin que se ernzumbe un proyecto nacional y regional con fuerza y consenso suficiente como para enfrentar los rápidos y profundos cambios de esta década de los 90. La incertidumbre y la perplejidad se hacen todavia más patentes al no tener Estados Unidos la capacidad de decisión económica que la AID le permitió en la década pasada. A esto se suma la inercia heredada de la administración Reagan-Bush, que dificulta los cambios.

Se debe reconocer, a pesar de todo, que en esta administración existe un nuevo profesionalismo politico en los principales dirigentes que se relacionan con América Latina y Centroamérica. Los ideólogos de la década pasada sólo mantienen activas algunas de sus reliquias, especialmente en el poder Legislativo. Estos nuevos profesionales en asuntos latinoamericanos de Washington han comenzado a olfatear la complejidad y las amenazas de la nueva realidad que se está pertilando en América Latina y sobre todo en Centroamérica.

El serio debate que se está realizando en diversas instancias de la administración Clinton, especifịcamente dentro de la AID, el Departamento de Defensa y el Consejo Nacional de Seguridad, demuestran la necesidad de revitalizar y reinventar la cooperación externa norteamericana. Hechos tan obvios como que en los últimos cinco años las exportaciones de los palses subdesarrollados con Estados Unidos han crecido más rápidamente que las exportaciones entre los megamercados, indican a estos expertos que los palses del Sur son fundamentales para la consolidación económica norteamericana. Las exportaciones norteamericanas a palses del Sur crecieron en un $106 \%$ enle 1986-91, pasando de 77 mil millones de dólares, llegando a alcanzar un $38 \%$ del total de las exportaciones norteamericanas. Estas exportaciones dan empleo a 3 millones de norteamericanos, lo que es clave en momentos en que el 
desempleo es uno de los cuellos de bolella más serios de la economia de Estados Unidos.

Eslos expertos se dan cuenta también que la cooperación externa norteamericana es de las más bajas del mundo desarrollado en relación a su PIB y tiende a decrecer, mientras que la cooperación japonesa supera ya la cooperación norteamericana. Son conscientes de que décadas de cooperación norteamericana a través de la AID han dejado en Africa y en América Latina situaciones tan críticas que la mayorla de la población está hoy en peores condiciones que hace 20 años. La ingobernabilidad y la inestabilidad en el Sur, especialmente en los vecinos palses de América Latina, se vislumbra ya como una amenaza.

Estos profesionales están hablando de "reinventar la cooperación" y la política exterior norteamericana en formas mucho más cooordinadas con los paises, superando el unilateralismo dominante en administraciones anteriores.

La nueva visión que Clinton anunció en su campaña electoral y que tantas expectativas despertó en América Latina y también en Nicaragua, tenía un sólido respaldo intelectual y profesional de connotadas personalidades, incluso del "establishment". Esta nueva visión aparece en dos importantes documentos de $1992^{5}$.

"Reinventando la ayuda externa" fue presentado el 22 de diciembre al Presidente eleclo Clinton. Se le proponia un nuevo liderazgo norteamericano basado en "la inversión en la gente, la protección de la tierra y el fortalecimiento de las instituciones democráticas". La globalización del mundo no se vela como una amenaza, sino como una "oportunidad sin precedentes" porque las politicas actuales de Estados Unidos se han desgastado y no responden a los intereses norteamericanos ni a los problemas globales. Por tanto, proponfan una polftica de "responsabilidad compartida" y de "intereses comunes" para garantizar la paz y el desarrollo en el perlodo de la postguerra frla.

"La pobreza y la masiva degradación ambiental" se plantean como las mayores amenazas contra la democracia. El hecho de que mil 200 millones de personas vivan en pobreza absoluta y que 18 millones mueran anualmente de hambre - lo que equivale a que cien aviones jumbos llenos

5* Reinventing Foreign AID: While Paper on U.S. Development Cooperation in a New Democratic Era. December 1992.

- Relining U.S. Interest in Latin America: a Strategy Paper. Institute for National Stralegic Studies. Office of the Secretary of Detense. February 1992. 
estallaran cada dia- es el hecho dominante de la década. La expansión del SIDA, la inestabilidad social, las actividades terroristas, el llujo de emigrantes y refugiados y el aumento del narcotráfico son vistos como consecuencias de este hecho lundamental: "Como la guerra fría fue el interés central de Estados Unidos en el pasado, estos hechos dominan el presente".

Esta realidad requiere un nuevo programa de desarrollo global. "Nuestra capacidad intelectual, conceptual y política está gastada, carece de coherencia y visión para enfrentar estas nuevas realidades". Para reslaurar la competitividad norteamericana se necesita la promoción de un desarrollo global sostenido. "Treinta años de experiencia han demostrado el completo fracaso de las políticas de desarrollo y la incapacidad de nuestra cortoplacista política exterior".

Este nuevo programa para el futuro que se le presentó al Presidente Clinton enfatiza en primer lugar la inversión en el pueblo y la educación, especialmente dirigida a las mujeres, para crear asI "empowerment", un poder y capacitación que permita a los pueblos enfrentarse a la revolución científica y tecnológica. La protección del ambiente y el ataque a la pobreza a través de una participación del pueblo son aspectos delerminantes para lograr este objetivo. Para enfrentar este reto se requiere la cooperación entre los palses desarrollados en una asociación de intereses comunes.

Esta nueva visión lue propuesta al Presidenle por un grupo de connotados políticos, intelectuales y empresarios norteamericanos, entre los que cabe destacar a Bryan Atwood, actual director de la AID; a Richard Feinberg, Presidente del Diálogo Interamericano y actualmente en el Consejo Nacional de Seguridad e incluso a Robert McNamara, exPresidente del Banco Mundial y ex-Secretario de Defensa.

La nueva visión que aparece en este documento coincide con la de otro documento presentado al Departamento de Delensa en febrero de 1992 y en la que se redelinen los nuevos intereses norteamericanos en América Latina. Ambos documentos ofreclan una visión de politica exterior que hubiese permitido una genuina Nueva Era en las relaciones de Estados Unidos con América Latina.

El eje del documento del Departamento de Defensa gira sobre la redefinición del nuevo concepto de seguridad en un mundo global. "La principal amenaza para Estados Unidos es actualmente su gradual pérdida de competilividad en el mundo y su fracaso para adaptarse a los cambios actuales".

Una América Latina estancada podría tener como consecuencia un 
mayor debilitamiento de la competitividad norteamericana y un flujo de recursos de los bancos y del presupuesto de defensa norteamericano para enfrentar los problemas de una región en crisis. El crecimiento económico de América latina y el fortalecimiento de su democracia son, por tanto, un interés vital para Washington. En especial, "los palses sobre de la cuenca del Caribe, nuestros más próximos vecinos y su lamentable situación económica presentan el mayor potencial de amenaza para Estados Unidos". "Centroamérica requerirá apoyo sustancial y continuo para enfrentar su inestabilidad social".

"Más aún, Centroamérica continúa sufriendo de sus clásicos males: la sobrepoblación y una grave disparidad social, que la convierten en un virtual museo para las politicas radicales, los liderazgos caudillistas, corrupción y las actitudes militares antidiluvianas".

Estos residuos de la guerra frla tienden a fomentar insurgencias, terrorismo, criminalidad y narcotráfico. Para enfrentar estas situaciones hay que superar "las inherentes deficiencias de una fragmentada política exterior solamente dirigida a solventar las crisis".

El documento concluye asegurando un "dramático aumento en la importancia de América Latina para Estados Unidos".

Qué ha sucedido con estas propuestas para una nueva estrategia lanzadas al inicio de la Administración Clinton? ¿Será que el ¿latln american lobby" es muy débil en Washington por no haber podido vincularse los gobiernos de América Latina con la comunidad latina en Estados Unidos? la realidad es que China, Rusia, Europa Oriental, Medio Oriente y Sudafrica han dominado la agenda internacional de la administración Clinton.

La dificil transición de la guerra fría a la globalización implica aceptar que Estados Unidos es hoy un pais en transicion. Este marco analítico es importante para Nicaragua, Centroamérlca y América Latina.

Encontrar las formas de incidir en las instituciones y en los nuevos profesionales norteamericanos es una tarea de mediano plazo, pero de importancia estratégica. Por otro lado, aunque parezca contradictorio y paradógico, importantes sectores opuestos al NAFTA están más cercanos a América Latina que grupos monopólicos propulsores del Tratado de Libre Comercio. El propio "caucus latinoamericano" se manifestó sin entusiasmo sobre la actual propuesta de NAFTA. El voto sobre NAFTA, cualquiera sea su resultado, este capltulo sino que abrirá nuevas perspectivas a la relación entre los palses del nuevo megamercado. 


\section{Nicaragua, noviombre 1993}

Las contradicciones actuales en América Latina son también fruto de una transición dificil y compleja que viejos esquemas de análisis en Estados Unidos tampoco ayudan a clarificar. El lenguaje, las promesas y el nuevo estilo de la administración Clinton no tienen contenido especifico ni propuestas suficientes para enfrentar las nuevas realidades de América Latina, en especial la de palses como Nicaragua, tan pequeños pero tan complejos" (Elliot Abrams).

La administración Clinton pretende eludir fácilmente las responsabilidades del gobiemo norteamericano en el pasado. La actual polarización de Nicaragua no es sólo un problema histórico y cultural de intolerancia politica que ha dominado al pais en el último siglo. Es también el producto de la politica injerencista y polarizante de los Estados Unidos, que exacerbó las contradicciones intemas.

En la década de los 80 no se bailó en Nicaragua un tango entre dos sino entre tres. El Sandinismo, la Resistencia y Estados Unidos fueron esos tres actores internos. Desde 1990 Washington afirma que el problema es sólo de los nicaragūenses, pero financió y apoyó a sectores especificos de la UNO que estaban en contra del gobiemo de Doña Violela. Las continuas visitas de los políticos de estos sectores de la UNO a Washington eran la clara demostración de esa injerencia, mientras en Managua no hubo embajador norteamericano durante más de un año.

La visita de Clifton Wharton en junio 1993, -que sorpresivamente renuncio-, y el nombramiento del nuevo Embajador en Managua, parecen abrir una nueva fase. Sin embargo Estados Unidos y América Latina se enfrentan simultáneamente a una transición dificil y compleja y no hay aún politicas definidas para el futuro. Mientras el Tratado de Libre Comercio (NAFTA) intenta definir hoy la agenda económica norteamericna, el dilema para Centroamérica sigue abierto: cómo consolidar la paz y la democracia a la vez que logra insertarse eficientemente en un mundo globalizado. Los ternas de nuestra agenda deberlan concentrarse en la búsqueda de un modelo de desarrollo capaz de generar crecimiento sostenible con empleo y equidad, en la formación del capital humano necesario para enfrentar la revolución tecnológica y la concentración y centralización del poder mundial, y en la integración latinoamericana capaz de fortalecer una genuina democracia continental.

Para Nicaragua en particular, el desalío es encontrar un consenso tripartito: Gobiemo-FSLN-UNO. Es una tarea dificil. Equivale nuevamente a intentar bailar un tango entre tres. El nuevo Embajador de Estados Unidos en Nicaragua pretende, desde su propio estilo, enseñar a bailar 
ese tango entre tres $y$, aprovechando las contradicciones intemas de las fuerzas en pugna imponer su propia agenda. Esto no dio resultado en el pasado.

El dilema para la actual misión diplomática norteamericana es cómo ser un representante activo de la Administración Clinton adoptando una nueva política de neutralidad constructiva, buscando hacer realidad la reiterada afirmación de que "el problema lo resuelven los nicaragũenses". Lo que le correspondería, para iniciar una nueva asociación democrática (partnership) sobre bases de respeto y autonomla, es facilitar y promover el diálogo nacional, sin pretender determinar su agenda.

A los nicaragūenses nos cortesponde consensuar nuestra propia agenda nacional, coincidente con una profunda integración cultural, política y económica con Centroamérica y el resto de América Latina y el Caribe. Sólo asi podremos situarnos e incidir en la transición norteamericana, sin quedamos reducidos a los márgenes que nos ofrezca un NAFTA, que tiene hoy posibilidades tan reducidas para la región.

¿Serán estas dos transiciones, la de América Latina y la de Norteamérica, conflictivas y antagónicas como en el pasado? ¿O pueden ser complementarias y asociadas en el siglo XXI? Dependerá de los nuevos sujetos sociales. Se requiere de nuevos sujetos, complementarios y no confrontativos, tanto en el Norte como en el centro y sur del conlinente. Es un desaffo mutuo y una común responsabilidad. 